\title{
Helix-Turn-Helix Motif
}

National Cancer Institute

\section{Source}

National Cancer Institute. Helix-Turn-Helix Motif. NCI Thesaurus. Code C13341.

A DNA binding domain comprised of two or more alpha helical amino acid sequences

that are linked by short flexible chains of amino acids. The interactions between the helices determine the domain structure and its DNA binding specificity. 